JOURNAL OF NURSING PRACTICE AND

EDUCATION, VOL. 02 NO. 01, DESEMBER 2021

DOI:10.34305/jnpe.v2i1.334
Ciptaandisebarluaskan di bawahLisensi

$\underline{\text { Creative Commons Atribusi-NonKomersial- }}$

BerbagiSerupa 4.0

\title{
PENGARUH PENGGUNAAN BUKU SDKI, SLKI, DAN SIKI TERHADAP \\ PENINGKATAN PENGETAHUAN PERAWAT DALAM MEMBUAT \\ DOKUMENTASI KEPERAWATAN BERBASIS SDKI, SLKI, DAN SIKI DI RUMAH SAKIT KMC KUNINGAN TAHUN 2021
}

Via Alfiyah Awaliyani, Aria Pranatha, Nur Wulan

STIKes Kuningan

via.alfiyahawaliyani@gmail.com

\begin{abstract}
Abstrak
Rumah sakit mempunyai peran penting dalam meningkatkan derajat kesehatan masyarakat, memberikan pelayanan kesehatan yang baik merupakan bentuk kepuasan bagi masyarakat. Asuhan keperawatan yang berkualitas menentukan pelayanan kesehatan yang berkualitas juga. Untuk membuat asuhan keperawatan yang berkualitas, perawat harus memiliki tingkat pengetahuan yang baik, khususnya pendokumentasian. penelitian ini bertujuan untuk mengetahui pengaruh penggunaan buku SDKI, SLKI, dan SIKI terhadap peningkatan pengetahuan perawat dalam membuat dokumentasi asuhan keperawatan berbasis SDKI, SLKI, dan SIKI di Rumah Sakit KMC Kuningan Tahun 2021.Desain penelitian ini adalah quasy eksperimen pretest and posttest with control group. Seluruh perawat rawat inap sebagai subjek penelitian. Teknik pengambilan sampel dengan total sampling sebanyak 36 orang. Instrumen yang digunakan adalah kuesioner pengetahuan yang berisi teori SDKI, SLKI, dan SIKI. Kemudian Dianalisis dengan menggunakan uji non parametrik Wilcoxon test dan independent paired t-test. Terdapat pengaruh penggunaan buku SDKI, SLKI, dan SIKI terhadap peningkatan pengetahuan perawat dalam membuat dokumentasi keperawatan berbasis SDKI, SLKI, dan SIKI di rumah sakit KMC Kuningan Tahun 2021. Hasil penelitian kelompok intervensi menunjukkan p-value 0,003 dan perbedaan kelompok intervensi dan kelompok kontrol menunjukkan $p$-value 0,0001 . Terdapat pengaruh yang signifikan terhadap peningkatan pengetahuan perawat pada kelompok yang diberikan intervensi penggunaan buku dan pelatihan buku SDKI, SLKI, dan SIKI dengan kelompok kontrol yang tidak diberikan intervensi dan pelatihan buku SDKI, SLKI, dan SIKI. Diharapkan perawat dapat mengikuti pelatihan secara periodik apabila pihak manajemen rumah sakit membuat program pelatihan terkait ketiga buku tersebut agar pengetahuan semakin bertambah.
\end{abstract}


JOURNAL OF NURSING PRACTICE AND

EDUCATION, VOL. 02 NO. 01, DESEMBER 2021

DOI:10.34305/jnpe.v2i1.334
Ciptaandisebarluaskan di bawahLisensi

Creative CommonsAtribusi-NonKomersial-

BerbagiSerupa 4.0

\section{Pendahuluan}

Rumah sakit adalah salah satu fasilitas pelayanan kesehatan yang memiliki peran penting dalam meningkatkan derajat kesehatan masyarakat (Mulyadi \& Katuuk, 2017).Upaya meningkatkan derajat kesehatan masyarakat, rumah sakit tentunya harus memiliki karakteristik dan organisasi yang kompleks.Pelayanan kesehatan merupakan bentuk pelayanan yang sangat berpengaruh pada tingkat kepuasan pasien, terutama pelayanan yang diberikan oleh tenaga keperawatan. Hal ini dibuktikan berdasarkan hasil penelitian oleh Rohim \& Pranatha, (2017) tentang Pengaruh Sistem Pemberian Pelayanan Keperawatan Profesional Metode Tim Terhadap Kepuasan Pasien dan Kepuasan Perawat di Instalasi Rawat Inap Rumah Sakit Umum Daerah 45 Kuningan, beliau mengemukakan bahwa persentase ketidakpuasan pasien terhadap pelayanan kesehatan sebesar 37,2\%. Faktor yang mempengaruhi ketidakpuasan pasien terhadap pelayanan kesehatan adalah kualitas pemberian asuhan keperawatan yang kurang optimal dan tidak dilaksanakan secara menyeluruh. Selain itu, terbatasnya jumlah perawat dan fasilitas sarana yang mendukung, kompetensi perawat yang belum terstandar, motivasi perawat yang kurang, fungsi manajemen pelayanan keperawatan belum optimal, belum adanya indikator mutu pelayanan keperawatan, dan tidak ada metode yang jelas dalam pemberian pelayanan keperawatan di rumah sakit sehingga permasalahan tersebut mengakibatkan pelayanan kesehatan masih bersifat okupasi (Rohim \& Pranatha, 2017). Berdasarkan Keputusan Menteri Kesehatan (KMK) RI Nomor HK.01.07/MENKES/425/2020 tentang standar profesi perawat menyebutkan bahwa daftar diagnosis keperawatan berisikan diagnosis keperawatan yang mengacu pada Standar Diagnosis Keperawatan Indonesia (SDKI) dan daftar keterampilan berisikan intervensi keperawatan yang mengacu pada Standar Intervensi Keperawatan Indonesia (SIKI).Dengan adanya aturan pemerintah terkait penggunaan buku SDKI dan SIKI ini, dapat meningkatkan kualitas asuhan keperawatan yang diberikan perawat di seluruh Indonesia (Gustinerz, 2020).

Berdasarkan hasil studi pendahuluan terhadap salah satu kepala ruangan rawat inap, didapatkan perawat tersebut sudah 
JOURNAL OF NURSING PRACTICE AND

EDUCATION, VOL. 02 NO. 01, DESEMBER 2021

DOI:10.34305/jnpe.v2i1.334

pernah mengikuti pelatihan mengenai askep berbasis SDKI, SLKI, dan SIKI.Akan tetapi, persentase sebanyak $100 \%$ perawat belum pernah mengikuti pelatihan secara langsung cara menggunakan buku SDKI, SLKI, dan SIKIdalam membuat dokumentasi keperawatan. Selain itu, RS KMC Kuningan masih menggunakan standar asuhan keperawatan berbasis Nanda Nic Noc dan dalam tahap penyusunan program penerapan standar asuhan keperawatan berbasis SDKI, SLKI dan SIKI.Sehingga peneliti tertarik untuk meneliti masalah tersebut.
Ciptaandisebarluaskan di bawahLisensi Creative Commons Atribusi-NonKomersialBerbagiSerupa 4.0

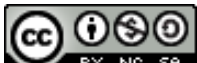

\section{Metode}

Metode penelitian yang digunakan adalah quasy eksperimen dengan rancangan pre test and post test with control group. Seluruh perawat rawat inap sebagai subjek penelitian. Teknik pengambilan sampel dengan total sampling sebanyak 36 orang yang dibagi dalam 2 kelompok yaitu kelompok intervensi dan kelompok kontrol. Instrumen yang digunakan adalah kuesioner pengetahuan yang berisi teori SDKI, SLKI, dan SIKI. Kemudian dianalisis dengan menggunakan uji non parametrik Wilcoxon test dan independent paired t-test.

\section{Hasil}

\section{Analisis Univariat}

Tabel 1. Gambaran pengetahuan perawat dalam membuat dokumentasi asuhan keperawatan berbasis SDKI, SLKI, dan SIKI di RS KMC Kuningan

tahun 2021 sebelum penggunaan buku SDKI, SLKI dan SIKI

pada kelompok intervensi dan kontrol

\begin{tabular}{lcccccc}
\hline Deskriptif Statistic & N & Min & Max & Mean & Median & $\begin{array}{c}\text { Std. } \\
\text { Deviation }\end{array}$ \\
\hline $\begin{array}{l}\text { Kelompok } \\
\text { Intervensi (Pre test) }\end{array}$ & 18 & 16 & 22 & 20.39 & 21.00 & 1.914 \\
$\begin{array}{l}\text { Kelompok Kontrol } \\
\text { (Post test) }\end{array}$ & 18 & 16 & 24 & 20.72 & 20.50 & 2.347 \\
\hline
\end{tabular}

Berdasarkan tabel 1 di atas, dari jumlah responden pada kelompok intervensi (pre test) sebanyak 18 orang didapatkan skor dengan nilai mean 20,39 dengan nilai median 21, nilai minimal 16 dan nilai maksimal 22. Adapun nilai standar deviasinya 1,914. Sedangkan, pada kelompok kontrol (post test) sebanyak 18 
JOURNAL OF NURSING PRACTICE AND

EDUCATION, VOL. 02 NO. 01, DESEMBER 2021

DOI:10.34305/jnpe.v2i1.334

orang didapatkan skor dengan nilai mean 20,72 dengan nilai median 20,50. Nilai
Ciptaandisebarluaskan di bawahLisensi

Creative CommonsAtribusi-NonKomersial-

BerbagiSerupa 4.0

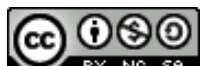

minimal 16 dan nilai maksimal 24.Adapun nilai standar deviasinya 2,347 .

Tabel 2. Gambaran pengetahuan perawat dalam membuat dokumentasi asuhan keperawatan berbasis SDKI, SLKI, dan SIKI di RS KMC Kuningan

tahun 2021 setelah penggunaan buku SDKI, SLKI dan SIKI

pada kelompok intervensi dan kontrol

\begin{tabular}{|c|c|c|c|c|c|c|}
\hline Deskriptif Statistic & $\mathbf{N}$ & Min & Max & Mean & Median & $\begin{array}{c}\text { Std. } \\
\text { Deviation }\end{array}$ \\
\hline \multicolumn{7}{|l|}{ Kelompok } \\
\hline $\begin{array}{l}\text { Intervensi } \\
\text { test) }\end{array}$ & 18 & 20 & 27 & 23.50 & 23.00 & 2.121 \\
\hline $\begin{array}{l}\text { Kelompok Kontrol } \\
\text { (Post test) }\end{array}$ & 18 & 16 & 24 & 20.72 & 20.50 & 2.347 \\
\hline
\end{tabular}

deviasinya 2,121. Sedangkan, pada

Berdasarkan tabel 2 di atas, dari kelompok kontrol (post) sebanyak 18 orang jumlah responden pada kelompok didapatkan skor dengan nilai mean 20,72 intervensi (post test) sebanyak 18 orang dengan nilai median 20,50. Nilai minimal didapatkan skor dengan nilai mean 23,50 16 dan nilai maksimal 24.Adapun nilai dengan nilai median 23, nilai minimal $20 \quad$ standar deviasinya 2,347.

dan nilai maksimal 27. Adapun nilai standar 
JOURNAL OF NURSING PRACTICE AND

EDUCATION, VOL. 02 NO. 01, DESEMBER 2021

DOI:10.34305/jnpe.v2i1.334
Ciptaandisebarluaskan di bawahLisensi

Creative Commons Atribusi-NonKomersial-

BerbagiSerupa 4.0

\section{Analisis Bivariat}

Tabel 3. Pengaruh penggunaan buku SDKI, SLKI, dan SIKI terhadap peningkatan pengetahuan perawat dalam membuat dokumentasi keperawatan berbasis SDKI, SLKI, dan SIKI di RS KMC Kuningan 2021 sebelum dan setelah diberikan pelatihan menggunakan buku SDKI, SLKI dan SIKI pada kelompok intervensi

\begin{tabular}{llllll}
\hline \multicolumn{1}{c}{ Data penelitian } & $\mathbf{N}$ & Mean & $\begin{array}{l}\text { Mean } \\
\text { selisih }\end{array}$ & P value \\
\hline $\begin{array}{l}\text { Kelompok } \\
\text { (Pre test })\end{array}$ & Intervensi & 18 & 20.39 & & 0,003 \\
$\begin{array}{l}\text { Kelompok } \\
\text { (Post test })\end{array}$ & Intervensi & 18 & 23.50 & & \\
\hline
\end{tabular}

Berdasarkan tabel 3 di atas, nilai mean pada kelompok intervensi (post test) terdapat peningkatan dibandingkan dengan kelompok (pre test) dengan selisih 3,11sehingga mendapatkan hasil nilai $\mathrm{p}(p$ value) sebesar 0,003. Maka keputusannya keputusannya $p$ value $<\mathrm{p}$ alpha $(0,05)$ sehingga dapat disimpulkan bahwa Ho ditolak dan Ha diterima. Artinya, terdapat pengaruh penggunaan buku SDKI, SLKI dan SIKI terhadap Tingkat Pengetahuan Perawat dalam Membuat Dokumentasi Keperawatan Berbasis SDKI, SLKI dan SIKI di RS KMC Kuningan Tahun 2021.

Tabel 4. Perbedaan penggunaan buku SDKI, SLKI, dan SIKI terhadap peningkatan pengetahuan perawat dalam membuat dokumentasi keperawatan berbasis

SDKI, SLKI, dan SIKI di RS KMC Kuningan 2021 yang tidak diberikan pelatihan menggunakan buku SDKI, SLKI dan SIKI pada kelompok intervensi dan kelompok kontrol

\begin{tabular}{lcccc}
\hline \multicolumn{2}{c}{ Data penelitian } & N & Mean & P value \\
\hline $\begin{array}{l}\text { Kelompok } \\
(\text { Post test })\end{array}$ & Intervensi & 18 & 23.50 & 0,0001 \\
$\begin{array}{l}\text { Kelompok } \\
\text { (Post test })\end{array}$ & Kontrol & 18 & 20.72 & \\
& & & &
\end{tabular}


JOURNAL OF NURSING PRACTICE AND

EDUCATION, VOL. 02 NO. 01, DESEMBER 2021

DOI:10.34305/jnpe.v2i1.334

Berdasarkan tabel4 diatas, hasil uji bivariat pada kelompok intervensi (post test) mendapatkan hasil mean 23,50 dan pada kelompok kontrol (post test) mendapatkan hasil mean 20,72 sehingga

\section{Pembahasan}

Analisis Univariat

Berdasarkan tabel 5.1 diketahui bahwa skor pengetahuan perawat sebelum penggunaan buku SDKI, SLKI, dan SIKI dengan 18 responden pada kelompok intervensi rata-rata sebesar 20,39 dan pada kelompok kontrol rata-rata sebesar 20,73.

Menurut Notoatmodjo, dalam Hakim, (2017)pengetahuan adalah hasil dari tahu yang artinya pengetahuan yang diperoleh hanya sebatas mengingat sesuatu yang telah dipelajari. Pengetahuan yang dimiliki oleh kelompok intervensi ataupun kelompok kontrol jika mengacu pada tingkatan pengetahuan maka berada pada kategori pengetahuan kurang.

Pengetahuan dipengaruhi oleh faktor internal dan eksternal, dalam penelitian ini faktor internal yang mempengaruhi pengetahuan yaitu usia, pendidikan, dan pengalaman atau masa kerja. Hal ini sejalan dengan yang ditemukan di RS KMC Kuningan, bahwa karakteristik perawat dalam penelitian ini
Ciptaandisebarluaskan di bawahLisensi

Creative CommonsAtribusi-NonKomersial-

BerbagiSerupa 4.0

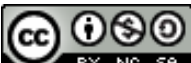

keduanya kelompok tersebut memiliki nilai p ( $p$ value) sebesar 0,001. Maka, dapat disimpulkan bahwa terdapat perbedaan skor pengetahuan pada kelompok intervensi dibanding kelompok kontrol. rata-rata berusia 20-30 tahun. Menurut Budiman \& Riyanto, (2013) dalam Ramadhani, (2019) faktor yang mempengaruhi pengetahuan salah satunya adalah usia. Semakin bertambahnya usia, maka daya tangkap dan pola pikir seseorang akan semakin berkembang.

Skor pengetahuan perawat sebelum penggunaan buku SDKI, SLKI, dan SIKI dengan 18 responden pada kelompok intervensi rata-rata sebesar 23,50 dan pada kelompok kontrol rata-rata sebesar 20,73. Berdasarkan hasil tersebut, adanya perbedaan antara kelompok intervensi dan kelompok kontrol.Nilai rata-rata kelompok intervensi lebih besar dibandingkan kelompok kontrol, artinya pengetahuan kelompok intervensi lebih baik dibandingkan dengan kelompok kontrol. Pengetahuan yang baik didasari dari sumber yang tepat dan pengalaman yang ia alami, dengan begitu untuk menghadapi situasi tertentu ia sudah mempunyai pengetahuan yang memadai juga dapat belajar dari pengalaman-pengalaman yang telah ia dapatkan sebelumnya. 
JOURNAL OF NURSING PRACTICE AND

EDUCATION, VOL. 02 NO. 01, DESEMBER 2021

DOI:10.34305/jnpe.v2i1.334

Sejalan dengan penelitian Sari et al., (2017)tentang perbedaan hasil belajar dengan menggunakan strategi pemanfaatan perpustakaan sekolah sebagai sumber belajar siswa, beliau mengemukakan bahwa pemanfaatan perpustakaan sebagai sumber primer untuk memenuhi kebutuhan informasi belajar akan membantu belajar lebih cepat.

Analisis Bivariat

Hasil penelitian bahwa sebelum dan setelah diberikan pelatihan menggunakan buku SDKI, SLKI, dan SIKI terdapat peningkatan pengetahuan perawat dalam membuat dokumentasi keperawatan berbasis SDKI, SLKI, dan SIKI.Nilai mean pada kelompok intervensi (post test) terdapat peningkatan dibandingkan dengan kelompok (pre test) dengan selisih 3,11. Hal ini dibuktikan dengan hasil uji paired ttest dengan $p$ value $=0,003<\mathrm{p}$ alpha $(0,05)$ artinya terdapat pengaruh penggunaan buku SDKI, SLKI, dan SIKI terhadap peningkatan pengetahuan perawat dalam membuat dokumentasi keperawatan berbasis SDKI, SLKI, dan SIKI di RS KMC Kuningan Tahun 2021 sebelum dan setelah diberikan pelatihan menggunakan buku SDKI, SLKI, dan SIKI pada kelompok intervensi.
Ciptaandisebarluaskan di bawahLisensi

Creative Commons Atribusi-NonKomersial

BerbagiSerupa 4.0

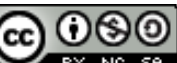

Berdasarkan hasil penyebaran kuesioner pengetahuan pada perawat terhadap buku SDKI, SLKI, dan SIKI di lima ruang rawat inap RS KMC Kuningan, rata-rata mengalami peningkatan yang signifikan setelah diberikan pelatihan menggunakan buku SDKI, SLKI, dan SIKI. Begitu pula sejalan dengan hasil penelitian Lusianah, (2008) dalam Hendriana \& Pranatha, (2019) bahwa terdapat hubungan antara kualitas dokumentasi asuhan keperawatan dengan pelatihan, kualitas dokumentasi akan meningkat sebesar 1,60 kali pada perawat yang pernah mengikuti pelatihan dibandingkan dengan perawat yang tidak pernah mengikuti pelatihan.

Berdasarkan hasil pemantauan oleh peneliti saat melakukan pendampingan pelatihan penggunaan buku SDKI, SLKI, dan SIKI dalam membuat dokumentasi asuhan keperawatan, masih banyak perawat yang belum mengetahui cara menggunakan buku tersebut. Maka, peran pendampingan dalam melatih perawat menggunakan buku SDKI, SLKI, dan SIKI sangat penting agar tidak salah tafsir. Hal tersebut didukung dari studi pendahuluan yang dilakukan oleh peneliti pada bulan April 2021 bahwa mereka hanya pernah mengikuti pelatihan melalui webinar yang diselenggarakan oleh PPNI sebanyak satu kali tentang buku 
JOURNAL OF NURSING PRACTICE AND

EDUCATION, VOL. 02 NO. 01, DESEMBER 2021

DOI:10.34305/jnpe.v2i1.334

SDKI, SLKI, dan SIKI tetapi belum pernah dan mengetahui cara penggunaan bukunya secara langsung.

Peneliti juga berpendapat ada faktor lain yang dapat meningkatkan pengetahuan yaitu ambisius atau ada keinginan mencoba terhadap sesuatu yang baru untuk menciptakan wawasan yang lebih luas. Menurut Pranatha, (2016) dalam Hendriana \& Pranatha, (2019) mengemukakan bahwa semakin tinggi pengetahuan seseorang maka sebanding dengan sikap positif yang dimilikinya. Tingkat pengetahuan termasuk ke dalam domain kognitif yang terdiri dari enam tingkatan yaitu pengetahuan, pemahaman, analisis, aplikasi, sintesis, dan evaluasi.Semakin tinggi tingkatan domain kognitif seseorang, maka semakin baik kemampuannya dalam melakukan penilaian terhadap sesuatu seperti menyebutkan, mendefinisikan, memahami, dan lain sebagainya.

Hasil penelitian bahwa terdapat perbedaan yang signifikan penggunaan buku SDKI, SLKI, dan SIKI terhadap pengetahuan perawat dalam membuat dokumentasi keperawatan berbasis SDKI, SLKI, dan SIKI pada kelompok intervensi dan kelompok kontrol. Hal ini dibuktikan dengan hasil uji paired t-test pada kelompok intervensi dan uji independen
Ciptaandisebarluaskan di bawahLisens

Creative CommonsAtribusi-NonKomersialBerbagiSerupa 4.0

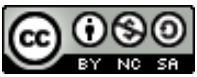

sampel t-testpada kelompok kontrol dengan $p$ value $=0,0001<\mathrm{p}$ alpha $(0,05)$.

Hal ini sejalan dengan penelitian Sulatri, (2012) dalam Lisa et al., (2019) menyatakan bahwa Thaha dan Ruseng yang menunjukkan terdapat perbedaan perubahan pengetahuan pada kelompok perlakuan lebih besar dengan nilai rata-rata 49,22 daripada kelompok kontrol dengan nilai rata-rata 17,36 . Hal ini sesuai dengan teori Sadiman et al., (2012) bahwa menggunakan objek langsung dalam pembelajaran sangat efektif terhadap tingkat daya serap dan ingat seseorang karena proses informasi melalui indera penglihatan dan pendengaran.

Menurut peneliti bahwa pemberian pelatihan buku pada kelompok intervensi sangat membantu mendapatkan pemahaman yang lebih nyata dan meningkatkan pengetahuan serta dapat mengaplikasikan ilmu yang diperoleh untuk membuat asuhan dokumentasi keperawatan yang lebih baik dibandingkan dengan kelompok kontrol yang pengetahuannya sebatas tahu dan ingat dari hasil pembelajarannya sebelumya, yaitu buku NANDA, NOC, dan NIC. Hal ini, bukan berarti pengetahuan seseorang yang belum menggunakan buku lebih rendah dari seseorang yang menggunakan ketiga buku tersebut, karena 
JOURNAL OF NURSING PRACTICE AND

EDUCATION, VOL. 02 NO. 01, DESEMBER 2021

DOI:10.34305/jnpe.v2i1.334

pada dasarnya buku SDKI, SLKI, dan SIKI tidak berbeda jauh dari buku NANDA, NOC, dan NIC, hanya saja berbeda pada penjabaran yang lebih terperinci, singkat, padat, dan jelas pada buku SDKI, SLKI, dan SIKI.

\section{Simpulan}

Berdasarkan hasil penelitian dan pembahasan, maka dapat disimpulkan bahwa gambaran pengetahuan perawat dalam membuat dokumentasi asuhan keperawatan berbasis SDKI, SLKI dan SIKI di RS KMC Kuningan tahun 2021 sebelum penggunaan buku SDKI, SLKI dan SIKI pada kelompok intervensi diketahui rata-rata sebesar 20,39 dan pada kelompok kontrol diketahui rata-rata sebesar 20,72. Jika dikategorikan, kedua kelompok tersebut berada pada pengetahuan kurang.

Gambaran pengetahuan perawat dalam membuat dokumentasi asuhan keperawatan berbasis SDKI, SLKI dan SIKI di RS KMC Kuningan tahun 2021 setelah penggunaan buku SDKI, SLKI dan SIKI pada kelompok intervensi diketahui rata-rata sebesar 23,50 dan pada kelompok kontrol diketahui rata-rata sebesar 20,72. Terdapat perbedaan antara kelompok intervensi (post test) dan kelompok kontrol.
Ciptaandisebarluaskan di bawahLisensi

Creative CommonsAtribusi-NonKomersial

BerbagiSerupa 4.0

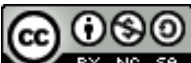

Terdapat pengaruh penggunaan buku SDKI, SLKI, dan SIKI terhadap peningkatan pengetahuan perawat dalam membuat dokumentasi keperawatan berbasis SDKI, SLKI, dan SIKI di RS KMC Kuningan Tahun 2021 dengan $p$ value $(0,003<0,05)$.

Terdapat perbedaan penggunaan buku SDKI, SLKI dan SIKI terhadap peningkatan pengetahuan perawat dalam membuat dokumentasi keperawatan berbasis SDKI, SLKI dan SIKI di RS KMC Kuningan Tahun 2021 pada kelompok intervensi dan kelompok kontrol dengan $p$ value $(0,0001<0,05)$.

\section{Saran}

Berdasarkan hasil dan pembahasan, peneliti memberikan saran bagi Kabid Keperawatan Rumah Sakit KMC Kuningan bahwa hasil penelitian ini diharapkan menjadi bahan kebijakan dalam membuat standar asuhan keperawatan berbasis SDKI, SLKI dan SIKI untuk meningkatkan pelayanan keperawatan dan mutu asuhan keperawatan terutama pendokumentasian dalam rekam medis. Selain itu, perawat rumah sakit KMC Kuningan dapat mengikuti pelatihan secara periodik apabila pihak manajemen rumah sakit membuat program pelatihan terkait buku SDKI, SLKI 
JOURNAL OF NURSING PRACTICE AND

EDUCATION, VOL. 02 NO. 01, DESEMBER 2021

DOI:10.34305/jnpe.v2i1.334

dan SIKI atau kegiatan lain yang terkait agar pengetahuan semakin bertambah meskipun rumah sakit belum menerapkan standar asuhan keperawatan yang telah ditetapkan.

Bagi Program Studi S1 Keperawatan STIKes Kuningan bahwa hasil penelitian ini diharapkan dapat digunakan untuk pengembangan ilmu pengetahuan dalam membuat dokumentasi asuhan keperawatan yang sudah terstandar berbasis SDKI, SLKI, dan SIKI di Sekolah Tinggi Ilmu Kesehatan Kuningan (STIKes Kuningan).

Bagi peneliti untuk menambah pengalaman dan wawasan dalam penerapan metode penelitian serta menjadi evidence based bagi peneliti selanjutnya dengan variabel dan desain penelitian yang berbeda.

\section{Daftar pustaka}

Gustinerz. (2020). Kemenkes: Standar Asuhan Keperawatan Mengacu Pada SDKI \& SIKI. Gustinerz.Com.

Hakim, M. L. (2017).Hubungan Tingkat Pengetahuan dengan Pemilihan Alat Kontrasepsi Intra Uteri Device (IUD) pada Ibu Post Partum di Ruang Ponek RSU Dr. Soeselo Slawi Tahun 2017. Sekolah Tinggi Ilmu Kesehatan Kuningan.

Hendriana, Y., \& Pranatha, A. (2019).Standar Nursing Language
Ciptaandisebarluaskan di bawahLisensi

Creative CommonsAtribusi-NonKomersial-

BerbagiSerupa 4.0

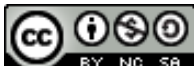

Berbasis NANDA, NOC, dan NIC

Terhadap Kualitas Pengisian

Dokumentasi

Keperawatan.NURSCOPE: Jurnal

Penelitian Dan Pemikiran Ilmiah

Keperawatan, 5(2), 26-31.

Lisa, U. F., Hernowo, B. S., \& Anwar, R. (2019).Pengaruh Penggunaan Media Video pada Pembelajaran Praktikum terhadap Pengetahuan dan

Keterampilan Mahasiswa dalam Penanganan Distosia Bahu di Universitas Ubudiyah Indonesia.Journal of Healthcare Technology and Medicine, 2(1), 4658.

Mulyadi, N., \& Katuuk, M. E. (2017).Hubungan Motivasi Kerja dengan Perilaku Caring Perawat di Instalasi Gawat Darurat dan Intensive Care Unit di RSU Pancaran Kasih Gmim Manado.Jurnal Keperawatan, $5(2)$.

Ramadhani, T. (2019).Hubungan Antara Pengetahuan Perawat IGD Dengan Keterampilan Dalam Pelaksanaan Triase Di Rumah Sakit Tipe C Di Wilayah Kabupaten Kuningan. Sekolah Tinggi Ilmu Kesehatan Kuningan.

Rohim, A., \& Pranatha, A. (2017).Pengaruh Sistem Pemberian Pelayanan Keperawatan Profesional Metode Tim Terhadap Kepuasan Pasien dan Kepuasan Perawat di Instalasi Rawat Inap Rumah Sakit Umum Daerah 45 Kuningan.Jurnal Ilmu Kesehatan Bhakti Husada: Health Sciences Journal, 6(2), 10-16.

Sadiman, A. S., Raharjo, R., Haryanto, A., \& Harjito. (2012). Media Pendidikan: Pengertian, Pengembangan, dan Pemanfaatannya. Jakarta: PT. Raja 
JOURNAL OF NURSING PRACTICE AND EDUCATION, VOL. 02 NO. 01, DESEMBER 2021

DOI:10.34305/jnpe.v2i1.334

Grafindo Persada.

Sari, K. A., Lusa, H., \& Yusuf, S. (2017).

Perbedaan Hasil belajar Dengan

Menggunakan Strategi Pemanfaatan
Ciptaandisebarluaskan di bawahLisensi

Creative CommonsAtribusi-NonKomersialBerbagiSerupa 4.0
Perpustakaan Sekolah Sebagai Sumber Belajar Siswa SDN Kota Bengkulu.Jurnal PGSD: Jurnal Ilmiah Pendidikan Guru Sekolah Dasar, 10(2), 